\title{
Uma Proposta de Framework em Gerência Estratégica de Redes Verticais
}

\author{
Alexandre Faria
}

\section{RESUMO}

Este artigo tem como objetivo compreender por que gerentes de rede implementam estratégias cooperativas que contribuem para o desempenho de redes verticais. A literatura no âmbito de redes reproduz a hegemonia gerencial que se constituiu na área de gerência estratégica. Influenciada pelo conceito de vantagem competitiva, esta hegemonia ajudou a dissolver a fronteira entre os domínios da estratégia e da gerência nos âmbitos da grande empresa e das redes verticais. Este artigo demonstra a importância do re-estabelecimento da fronteira entre estratégia e gerência para esse tipo de investigação. Com base em extensa investigação empírica baseada na ontologia do realismo crítico, o autor propõe um framework cuja principal característica é o reconhecimento de dois níveis de redes: as supra-redes e as redes gerenciais. A proposta desafia o desprezo de pesquisadores pelo caráter político da estratégia e pelas interfaces de governo e empresa, e as disputas entre as principais escolas teóricas em gerência estratégica. No final, o autor sugere que o framework deve ser explorado no Brasil por pesquisadores e praticantes relacionados aos âmbitos privado e público.

Palavras-chave: gerência estratégica; redes verticais; realismo crítico.

\begin{abstract}
This article aims at understanding how managers of networks implement cooperative strategies that enhance the overall performance of vertical networks. The literature on networks reproduces the managerial hegemony that has been built in the area of strategic management. Influenced by the concept of competitive advantage this hegemony helped dissolve the boundary between the domains of strategy and management within large companies and vertical networks. This article shows the importance of reestablishing the boundary between strategy and management for this sort of investigation. Grounded on an extensive empirical investigation which followed the basic tenets of critical realism, the author proposes a framework which recognizes two levels of networks - the supra-networks and the managerial networks. The proposal challenges the dismissal of the political feature of strategy and the business-government interfaces, and the disputes between the main schools of thought in strategic management. At the end, the author suggests that the framework should be used in Brazil by researchers and practitioners related to public and private domains.
\end{abstract}

Key words: strategic management; vertical networks; critical realism. 


\section{INTRODUÇÃO}

Em resposta às demandas competitivas do mercado global, conglomerados construíram redes de fornecimento em diversos países. De acordo com o princípio de 'cooperar para competir', a competição pelo mercado passou a ser feita não mais somente por empresas individuais mas principalmente por essas redes verticais (Hitt, Ireland, \& Hoskisson, 2002). Essas redes ainda são um desafio na área de gerência estratégica. Duas das principais dificuldades enfrentadas pelos pesquisadores são o paradigma 'da empresa como entidade autônoma em face do ambiente externo ou em busca de vantagem competitiva' que a academia ajudou a estabelecer.

Na literatura temos visto um debate análogo aos debates 'estratégia' versus 'estrutura' e 'de-dentro-para-fora' versus 'de-fora-para-dentro' (Whittington, 2001): os autores mais otimistas prescrevem como e por que as redes devem gerar vantagens competitivas (Lorenzoni \& Baden-Fuller, 1995), enquanto os autores céticos argumentam que redes são estruturas complexas demais para serem gerenciadas (Axelsson \& Easton, 1992).

As redes são desafiantes porque provocam os pressupostos teóricos quanto ao que é empresa e ao que é ambiente ou mercado. Correspondentemente, as redes também desafiam o que é público ou privado. Essas questões ajudam a explicar por que pesquisadores não têm conseguido esclarecer como e por que as redes influenciam o desempenho competitivo de empresas ou indústrias.

No setor automotivo a implementação de estratégias em redes não tem sido fácil. Um dos obstáculos é o histórico de conflitos entre montadoras e fornecedores, os quais são explicados em grande parte pelo paradigma 'da empresa como entidade autônoma'. Para viabilizar a gerência estratégica das redes, e reproduzindo de certa forma o princípio de que 'a estrutura segue a estratégia', algumas empresas fornecedoras foram transformadas em gerências de redes pelas montadoras. Alguns fornecedores - os gerentes de rede - ganharam status estratégico, enquanto a maioria passou a ter (ou continua tendo) status operacional. Esses gerentes devem tanto cooperar com as montadoras quanto eliminar conflitos nos níveis inferiores das redes (Lamming, 1993). As idéias são simples; porém, assim como a maioria dos modelos em gerência estratégica, a efetiva implementação tem sido marcada por ceticismo e dificuldades.

Preocupados com a baixa relevância do conhecimento acadêmico em gerência estratégica (Rumelt, 1996) e atentos à dissolução de fronteiras entre empresas e 
entre estas e o mercado, alguns pesquisadores defenderam recentemente a constituição da 'escola de fronteiras' (ver Foss, 2001). A principal preocupação dessa escola é que a dissolução de fronteiras de empresas e de mercados torna complexa não somente a prática da estratégia, mas também sua análise. Seus defensores argumentam que pesquisadores devem ocupar-se menos em prescrever sobre as redes, e mais em compreender como se dá sua gerência estratégica.

$\mathrm{Na}$ área de marketing o cenário é parecido. Também preocupados com a relevância da disciplina, autores argumentam que a desfronteirização dos mercados, a desconglomeração das grandes empresas e a formação de redes no mercado global a partir dos anos 90 exigem a dissolução das antigas fronteiras entre estratégia e marketing (Webster, 1992). Esses autores prescrevem a orientação para o mercado como diretriz estratégica única (Dobnie \& Lufman, 2000) e defendem a produção de conhecimento relevante para a gerência das redes. Esse foco gerencial ganhou a adesão até mesmo de pesquisadores europeus que se opunham, até o início dos anos 90, ao propósito de construir modelos gerenciais no âmbito de redes (Hakansson \& Ford, 2002).

Ao privilegiarem o foco gerencial e simplificarem as complexidades trazidas pelo mercado global, os pesquisadores dessas áreas reproduzem no âmbito de redes a hegemonia gerencial que se construiu na literatura. Uma das principais características dessa hegemonia é a supressão de questões de poder e de política referentes a diferenças hierárquicas e de interesses entre 'gerentes' e 'estrategistas'. De fato, a literatura não reconhece um dos principais desafios para gerentes de redes em diferentes países: conciliar as demandas de empresas compradoras extremamente poderosas e de empresas fornecedoras locais (ou não) menos poderosas.

No início dos anos 90, pesquisadores vinculados ao chamado critical management studies defenderam o restabelecimento da fronteira entre 'estrategistas' e 'gerentes'. Eles argumentam que o conhecimento dominante em gerência estratégica, por servir ao interesse de dominação dos gerentes pela alta cúpula, precisa ser revisto (ver Alvesson \& Willmott, 1996). A pesquisa crítica em estratégia deve promover a emancipação, em oposição à dominação, dos gerentes.

Essa abordagem crítica, que vem ganhando tanto adeptos quanto oponentes na academia, ainda não foi aplicada ao âmbito específico das redes. Mediado pela ontologia do realismo crítico, este artigo adota a perspectiva dos gerentes de redes e propõe no final um framework que busca explicar melhor como e por que estratégias cooperativas em redes verticais são gerenciadas. 
Este artigo está dividido em cinco seções. Na segunda o autor descreve como os conceitos de competição e de vantagem competitiva ajudaram a consolidar a hegemonia gerencial na literatura de gerência estratégica a partir dos anos 80 e como isso vem afetando a pesquisa no âmbito de redes. Em seguida o autor desenvolve uma abordagem crítica para conceituar e investigar a gerência estratégica de redes. $\mathrm{Na}$ terceira o autor descreve a metodologia da pesquisa, baseada na ontologia de realismo crítico. Na quarta são apresentados e analisados os principais resultados e é proposto um framework focado em supra-redes e redes inter-firma. Na última seção o autor apresenta as considerações finais e sugestões para pesquisas futuras.

\section{A Hegemonia Gerencial e a Crítica no Âmbito de Redes}

Esta seção é dividida em dois blocos. No primeiro, é demonstrado como os conceitos de competição e de vantagem competitiva ajudaram a consolidar a hegemonia gerencial nas literaturas de estratégia e de marketing e, correspondentemente, no âmbito de redes. No segundo, é ressaltada a importância dos argumentos de autores do critical management studies para a construção de conhecimento relevante sob a perspectiva dos gerentes de redes.

\section{Um Histórico da Literatura de Redes}

Nos anos 60, após a Segunda Guerra, o trabalho de Chandler (1962) apontou que a condução estratégica das grandes empresas nos EUA que adotaram a estrutura multidivisional era a principal causa do progresso daquele país. Com esse influente trabalho, desenvolvido no MIT e difundido no meio acadêmico por meio e a partir de teses de doutorado produzidas em Harvard, Chandler ajudou a posicionar a disciplina de estratégia como a mais importante da academia de administração e a legitimar, primeiramente nos EUA e depois em diversos países, o princípio do 'comando e controle': ou seja, o de que 'a estrutura segue a estratégia'.

Líderes de grandes empresas passaram então a ser representados como comandantes capazes de promover o progresso industrial e nacional por meio de estratégias voltadas para o lucro no longo prazo. Em oposição aos temores de que os grandes conglomerados trariam prejuízos para o mercado e sociedade, o trabalho de Chandler mostrou que as estratégias de longo prazo, os gerentes e as estruturas hierárquicas correspondentes garantiriam tanto o crescimento das grandes empresas quanto o desenvolvimento econômico. 
O trabalho de Chandler não pode ser avaliado como isento de influências do contexto em que foi produzido. Seu trabalho desafiara a importância do Estado para o desenvolvimento econômico do país que vencera a Segunda Guerra e que buscava, no contexto da Guerra Fria, uma solução para a rivalidade entre governo e empresa (Dunlop, 1980). Esse trabalho ajudou a inaugurar no Ocidente a ideologia do capitalismo gerencial (Chandler, 1962), posicionar a grande empresa como instituição tão poderosa quanto o Estado, ressaltar a importância da elite corporativa, e a estabelecer o paradigma da empresa 'como entidade autônoma em face dos desafios do ambiente externo'. Em outras palavras, o trabalho de Chandler ajudou a forjar a mística da gerência americana (Locke, 1996) e a constituir a principal abordagem teórica e o principal modelo na área: a abordagem clássica (Whittington, 2001) e o planejamento estratégico (Mintzberg, 1990).

A emergência do conceito de competição na literatura de estratégia a partir da primeira metade dos anos 80 , impulsionada principalmente pela 'invasão japonesa' ao mercado de automóveis dos EUA, desafiou o trabalho de Chandler e a hegemonia do modelo de planejamento estratégico. As ênfases da estratégia passaram a ser a sobrevivência e a competição e não mais o lucro e o crescimento no longo prazo. O modelo de cinco forças desenvolvido por Porter (1980) - "sem experiência alguma no campo ... (desde 1973) como professor na Harvard Business School" (Aktouf, 2002, p. 44) - ofuscou as preocupações com o poder de mercado da grande empresa, ao estabelecer uma nova era nos EUA e no mundo: a da estratégia competitiva.

Esse modelo de Porter ajudou a promover a idéia de que para superar as pressões competitivas era necessário substituir o plano estratégico centralizador pelo pensamento estratégico descentralizado(r). Em outras palavras, a estratégia competitiva pressupõe a dissolução de fronteiras intra-organizacionais e a delegação de responsabilidades estratégicas para aqueles que de fato conhecem os mercados fornecedores em que competem.

O mundo dos negócios passou a ser representado como um cenário de guerra na literatura dos EUA a partir da segunda metade dos anos 80. Autores de diferentes escolas passaram a prescrever que as grandes empresas, ameaçadas pela crescente concorrência internacional, deveriam construir vantagens competitivas que fossem sustentáveis. Tanto o modelo de cadeia de valor (Porter, 1985) quanto a escola de recursos (Wernerfelt, 1984), por exemplo, defendiam que todas as funções e níveis da grande empresa deveriam cooperar entre si. Isso ajudou a dissolver ainda mais a fronteira entre 'estratégia' e 'gerência' e a suprimir questões de poder e políticas entre a alta cúpula e (a) unidades de negócios, (b) funções gerenciais, e (c) constituintes externos. 
Os conceitos de estratégia competitiva e de vantagem competitiva consolidaram o paradigma da 'empresa como entidade autônoma em busca de vantagens competitivas' e ajudaram a consolidar a hegemonia gerencial na literatura. Pesquisadores das disciplinas funcionais passaram a tratar interesses estratégicos das grandes empresas como interesses de todos e suprimiram questões de poder e políticas entre as áreas funcionais da gerência e a área de estratégia, assim como entre subsidiárias e matriz. Na área de marketing o conceito de orientação para o mercado (Kohli \& Jaworski, 1990) ilustra o alcance da influência desse tipo de bagagem (ver Faria, 2004a).

Com base no êxito das empresas japonesas do setor automotivo, alguns autores foram um pouco além e argumentaram que os modelos de cadeia de valor e orientação para o mercado deveriam estender-se ao âmbito interfirma. Em paralelo à difusão do princípio de 'cooperar para competir', liderado por montadoras, foi então difundido o modelo de gerência de cadeia de fornecedores ou do 'fornecimento enxuto' (Womack, Ireland, \& Hoskisson, 1990). Essas bagagens foram automaticamente estendidas para o contexto internacional, em consonância com argumentações feitas por Porter no início dos anos 90 a respeito das novas regras competitivas do chamado 'mercado global'. Segundo o autor as vantagens 'comparativas' dos países já não faziam tanta diferença para o desempenho das grandes empresas por causa da globalização dos mercados de produção e consumo de bens e serviços (Porter, 1990).

O êxito dos japoneses nos mercados de automóveis dos EUA e da Europa foi exaustivamente usado por diferentes autores para demonstrar que, na era da globalização, a não dissolução das fronteiras entre os mercados nacionais de produção e de consumo reduziria a competitividade das empresas. Segundo analistas, se isso não fosse reconhecido, os japoneses acabariam derrotando os conglomerados industriais do Ocidente com facilidade. Esses argumentos extremos ajudaram a elevar a importância da cooperação e das redes e também da dissolução de fronteiras nacionais na literatura de estratégia.

Essas bagagens tiveram conseqüências importantes na academia. Ao longo dos anos 90, foram amalgamados os conceitos de gerência de marketing, estratégia de marketing e gerência estratégica; o mesmo ocorreu com os de gerência de operações, estratégia de operações e gerência estratégica. Tudo (ou quase tudo) passou a ser tratado como 'estratégico' nas diferentes literaturas, que enfatizavam o papel do gerente. Os excessos correspondentes ajudam a explicar por que autores vêm reclamando que não se sabe mais o que é estratégia (Whittington, 2001) nem sua contribuição efetiva para o desempenho das empresas (Porter, 1996). 
Em paralelo, houve a explosão de redes verticais, lideradas principalmente por grandes montadoras do setor automotivo, em diversos países. Para contornar o histórico de conflitos, fornecedores diretos foram transformados em gerentes de rede. O modelo foi exportado para países e setores, tais como o de telecomunicações e eletrônica e diversos fornecedores locais foram substituídos ou adquiridos por fornecedores de outros países. Apesar da importância dessas transformações e de suas implicações, pouco se sabe sobre a condução estratégica dos gerentes de redes e a influência das redes para o desempenho de empresas ou indústria (Gulati, Nohria, \& Zaheer, 2000).

Mais especificamente, pouco ainda se sabe sobre como e por que gerentes de redes implementam estratégias cooperativas com montadoras e fornecedores que levam ao aumento do desempenho competitivo das redes. A compreensão desses processos é relevante não somente para pesquisadores e gerentes, mas também para empresas internacionais e locais e ainda para instituições e agentes comprometidos com o desenvolvimento nacional ou local.

\section{A Abordagem Crítica em Estratégia em Redes Verticaiss}

Com base nos argumentos de pesquisadores vinculados ao critical management studies acerca do caráter político do conhecimento acadêmico em estratégia, é possível afirmar que o processo de constituição da hegemonia gerencial na área de estratégia se deu contrariamente aos interesses mais genuínos da gerência (Shrivastava, 1986). Baseados na teoria de interesses cognitivos de Habermas (1987), esses pesquisadores argumentam que esse tipo de conhecimento acadêmico, por escamotear ideologias, interesses e mecanismos de dominação que prejudicam a maioria (a gerência), é conveniente para alguns poucos (a elite corporativa). Por essa razão, eles defendem a produção de conhecimento que promova a emancipação do gerente (Alvesson \& Willmott, 1996).

Pesquisadores críticos advertem que a ciência costuma ser usada para legitimar interesses específicos que são contrários aos da maior parcela da sociedade. Conseqüentemente, o objetivo principal da teoria crítica não é simplesmente espelhar ou descrever a 'realidade' social como ela é, mas buscar a modificação da realidade. A teoria crítica se dedica a "explicar o que está errado com a realidade social corrente ... e fornecer normas claras para a crítica e objetivos práticos para o futuro" (Bohman, 1996, p. 190). No entanto uma das características mais fortes da teoria crítica é a inexistência de consenso entre seus autores sobre o nível da realidade que deve ser modificada e sobre quais e como as mudanças devem ocorrer.

Para a maioria dos autores críticos, conhecimento é um recurso de central importância tanto para a dominação quanto para a emancipação dos atores sociais. 
De acordo com Habermas, um dos mais representativos teóricos da Escola de Frankfurt, três tipos de interesse governam a produção de conhecimento e a apreensão da realidade: (a) o técnico; (b) o prático, e (c) o emancipatório. O primeiro capacita a espécie humana a um certo controle de dimensões da natureza e da sociedade; esse tipo de conhecimento está associado ao uso autoritário de artefatos e conceitos vinculados, por exemplo, à administração científica de Taylor. O segundo foca na dimensão intersubjetiva e segue o argumento de que a execução de qualquer tarefa exige o entendimento mútuo dos constituintes da organização; esse tipo de conhecimento está associado a abordagens comportamentais mais 'ingênuas' em administração (ver Alvesson \& Willmott, 1992). O terceiro busca revelar e transcender formas de organização que promovem e legitimam restrições ao potencial humano e ao exercício pleno da autonomia.

Apesar da importância desse tipo de argumentação acerca do conhecimento, problemas epistemológicos também afetam pesquisadores críticos. Pesquisadores críticos mais radicais poderiam, por exemplo, propor e concluir de forma precipitada que gerentes de redes implementam estratégias cooperativas porque são dominados pelas montadoras. Entretanto, análises críticas que privilegiam o poder da dominação ou do dominador costumam ignorar as estratégias e os interesses do aparentemente dominado (Alvesson \& Deetz, 2000). De fato, 'dominados' também exercem o papel de dominadores em redes verticais. Correspondentemente, o autor deste artigo defende o uso da ontologia do realismo crítico para orientar a metodologia dessa pesquisa.

\section{A Metodologia de Pesquisa}

A investigação revista neste artigo tinha como principal objetivo descobrir se gerentes de rede implementam estratégias cooperativas por causa da autoridade da montadora, da dominação da montadora, da importância competitiva atribuída à rede, ou por alguma outra causa, conhecida ou não pela empresa ou pelo pesquisador. O conhecimento acadêmico em estratégia - tendo em vista a posição hierárquica da disciplina e sua histórica vinculação às elites e ao poder militar está longe da neutralidade (Knights \& Morgan, 1991; Martin, 2003). Argumento similar se aplica à área de marketing (Wensley, 1995). A maioria das pesquisas nessas duas áreas se caracteriza pela imposição de teorias sobre dados empíricos (Mir \& Watson, 2000) e pela busca de regularidades observáveis ou 'empíricas' por meio da aplicação de testes estatísticos.

Ao invés de um 'espelho' da realidade, a verdade para pesquisadores dessas áreas é muito mais "uma questão de convenção" (Sayer, 1992, p. 75). Baseado 
na ontologia de realismo crítico, a principal orientação epistemológica nessa investigação foi desafiar as aparências e os conhecimentos estabelecidos, para que fosse possível descobrir a realidade - a qual existe independentemente de nossos conhecimentos ou conceitos sobre ela (Bhaskar, 1989). Esse processo de descoberta seguiu o critério de plausibilidade, o qual estabelece que uma boa descrição da realidade é alcançada; quando os mecanismos e as estruturas postulados são capazes de explicar fenômenos de interesse, temos boas razões para acreditar em sua existência, e não podemos pensar em alternativas igualmente boas (Bhaskar, 1997, p. 58).

O realismo crítico pressupõe que a realidade existe e que em grande medida esta independe de nosso conhecimento, interpretação ou observação. Seus autores desafiam o paradigma positivista de que a regularidade de eventos observáveis nos leva à identificação de 'leis causais' no mundo social por meio de uma proposta ontológica específica. A realidade é composta de estruturas e mecanismos causais que se dispõem verticalmente e segundo uma lógica de estratificação. Conseqüentemente, a atenção do pesquisador deve mover-se desde o fluxo de eventos mais visíveis/observáveis até os "mecanismos causais, estruturas sociais, poderes e relações que governam tais eventos" (Ackroyd \& Fleetwood, 2000, p. 13).

Outro pressuposto do realismo crítico é que as razões produzidas ou reproduzidas por informantes, empresas, ou acadêmicos, não devem ser tidas como causas nem como 'neutras'. Correspondentemente, a tarefa de tentar descobrir mecanismos e estruturas causais - ou seja aquilo "que 'faz com que aconteça', que 'produz', 'gera', cria', ou 'determina' isso ou aquilo, ou, mais fracamente, que 'permite' ou 'leva a' isso ou àquilo" (Sayer, 1992, p. 104) - não se reduz a conhecer as razões usadas ou preferidas pelos agentes ou identificar as regularidades 'empíricas' correspondentes.

Isso não quer dizer que as razões usadas pelos agentes não são importantes; tampouco quer dizer que não são importantes as razões concebidas ou testadas pelo pesquisador. Agentes sociais têm conhecimento de muitos ou de alguns dos mecanismos e estruturas causais que estão por trás de ações e de fenômenos observáveis ou não observáveis. Porém, as principais causas costumam ser desconhecidas pelos agentes sociais. Ademais, a atribuição de razões por esses agentes sociais não é necessariamente uma atividade neutra.

Três domínios de realidade são concebidos pelo realismo crítico. O 'real', o domínio no nível mais elevado, é formado por redes, agentes, mecanismos e estruturas não necessariamente empíricas, as quais tomam a forma de eventos no domínio seguinte ('o factual'). Alguns destes eventos são manifestados no nível da experiência ('o empírico’), outros não. O domínio do empírico é tratado 
como "um subconjunto do factual, o qual é em si um subconjunto do real" (Bhaskar, 1989, p. 100). Diferentes estruturas podem existir, mas contra-agir e, conseqüentemente, produzir 'não eventos' no nível do factual. De forma análoga, eventos podem ocorrer sem que sejam experimentados (Bhaskar, 1989, p. 16) no nível correspondente.

Os sinais da Tabela 1 ('v') indicam o domínio de realidade no qual mecanismos, eventos e experiências respectivamente residem, bem como os domínios envolvidos para que tais 'residências' sejam possíveis. Experiências, por exemplo, são eventos que são identificados no domínio do empírico. Tais experiências pressupõem a ocorrência de eventos e ações no domínio do factual, independentemente de nossa observação ou de nosso conhecimento deles no nível do empírico. Por sua vez, eventos pressupõem a existência de mecanismos e estruturas no domínio do real que foram responsáveis pela geração desses eventos e de outros que eventualmente não são identificados (ver em Tsoukas, 1994, p. 291).

\section{Tabela 1: Bases Ontológicas do Realismo Crítico}

\begin{tabular}{lccc}
\hline & $\begin{array}{c}\text { Domínio } \\
\text { do Real }\end{array}$ & $\begin{array}{c}\text { Domínio } \\
\text { do Factual }\end{array}$ & $\begin{array}{c}\text { Domínio } \\
\text { do Empírico }\end{array}$ \\
\hline Mecanismos/estruturas/poder/relações & $\mathbf{v}$ & & \\
Eventos e ações & $\mathbf{v}$ & $\mathbf{v}$ & \\
Experiências/percepções & $\mathbf{v}$ & $\mathbf{v}$ & $\mathbf{v}$ \\
\hline
\end{tabular}

Fonte: adaptação do autor a partir de Tsoukas (1994, p. 291) e Ackroyd e Fleetwood (2000, p.13).

A investigação seguiu um desenho de casos múltiplos e incorporados (Yin, 1994), com o objetivo de desenvolvimento teórico (Eisenhardt, 1989). Os casos foram investigados no Brasil e na Inglaterra $-80 \%$ dos casos no setor automotivo e $20 \%$ no setor de telecomunicações - e analisados ao longo de três anos. O trabalho de campo começou na Inglaterra e totalizou mais de setenta horas de contatos diretos com gerentes das empresas de cada caso - em total de cinco - e mais de cinqüenta visitas aos seus correspondentes locais de operações, nos dois países.

Cada caso investigado era composto de um gerente de rede, uma montadora, e um ou dois fornecedores desse gerente de rede. As primeiras entrevistas foram feitas com informantes das montadoras que aceitaram participar da pesquisa. Cada um desses informantes indicou dois gerentes de rede que tinham implementado estratégias cooperativas compatíveis com a pergunta de pesquisa. Para a escolha dos gerentes de rede o pesquisador usou o procedimento de casos polares (Pettigrew, 1992a): ou seja, cada informante teve que indicar gerentes de rede que fossem classificados pela montadora como 'tipos opostos'. 
Os gerentes de rede foram contactados e as entrevistas passaram a ser feitas com os informantes-chave. Foram entrevistados diretores e gerentes mais relacionados às áreas de vendas e de marketing. Os 'outros lados da história' foram reconhecidos por meio da comparação cuidadosa das narrativas dos informantes-chave e as dos informantes das outras empresas de cada rede. Ao longo da investigação, outros informantes dos gerentes de rede foram entrevistados para esclarecer contradições entre as narrativas.

Em pesquisas na área de decisão estratégia a memória de informantes costuma ser um problema sério, assim como a atribuição de significados a posteriori (Golden, 1997). Essas questões são ainda mais complicadas, quando a pesquisa é do tipo cross-cultural, e enfatiza questões de poder e política no âmbito de redes. Informantes tendem a esquecer algumas coisas ou a 'inventar' outras em suas narrativas. O procedimento de episódios críticos (Easterby-Smith, Thorpe, \& Lowe, 1991) foi então usado para aumentar o controle nas entrevistas e na análise dos resultados.

Esse procedimento ajudou os informantes, em especial os informantes-chave, a descrever e a explicar cada caso com a máxima precisão. As entrevistas foram baseadas em roteiros semi-estruturados, que foram construídos a partir da análise de cada entrevista com o informante-chave e com os informantes das outras empresas. Esse procedimento incremental de coleta e triangulação ajudou o pesquisador a manter o controle da investigação (Miles \& Huberman, 1994) e a identificar e interpretar interesses e teorias mobilizados por informantes.

Seguindo o critério de plausibilidade, o pesquisador usou outras fontes de evidências, tais como relatos de informantes de empresas que não faziam parte da rede investigada, membros de sindicatos de trabalhadores e de associação de classe, e especialistas nos setores. O pesquisador também usou outras bagagens teóricas, tais como economia política internacional e sociologia global (Sklair, 1995) para analisar os casos investigados. Finalmente, o pesquisador debateu os resultados e os desenvolvimentos analíticos com acadêmicos e não-acadêmicos na Inglaterra e no Brasil antes de se avaliar como capaz de descrever e explicar a realidade.

\section{Principais Resultados e Desenvolvimentos Analíticos}

Esta seção está dividida em três itens. No primeiro o autor descreve e analisa os principais resultados da pesquisa empírica. Nos dois itens seguintes o autor propõe um framework, baseado na pesquisa empírica e na ontologia do realismo crítico. 


\section{Descobertas Empíricas}

As descobertas mais importantes surgiram no Brasil, quando o pesquisador teve acesso a narrativas que transitavam com facilidade desde o domínio do empírico até o do real. Sob essa perspectiva, os doze meses anteriores de pesquisa na Inglaterra pareceram pouco reveladores. Devido às descobertas no Brasil, os dez meses seguintes de trabalho de campo na Inglaterra foram então marcados por descobertas igualmente importantes.

Dois episódios no Brasil merecem destaque. Primeiro, um informante-chave argumentou, de forma irônica, que 'negociações (entre montadoras e fornecedores) nunca acontecem sem blefes... (por isso) você não pode acreditar nos procedimentos contábeis e relatórios que vir à sua frente' [acompanhado de um sorriso irônico]. Essa declaração ilustra como informantes no Brasil se preocupavam pouco em 'gerenciar' as entrevistas por meio do uso de discursos estabelecidos em comparação com os informantes na Inglaterra.

Em fase posterior da investigação no Brasil, um diretor de uma das montadoras analisadas também surpreendeu o pesquisador com narrativas desse tipo: 'todos esses procedimentos de qualidade que a matriz inventou de trazer para cá (para o Brasil) não são utilizados. Essa papelada toda na minha mão... esses formulários para avaliação de qualidade de nossos fornecedores... não serve para nada. Tudo isso é muito importante para a mídia e para o governo, entende? Nosso vice-presidente de compras, que veio da matriz, está à frente dessa estratégia... ele é um 'showman' [risos]... ele está todo o tempo com os governantes e na mídia, entende? ...'. [demonstrando descontentamento].

Mais adiante o informante criticou a introdução de sistemas de informação e de monitoramento, porque estes reduziam a autonomia estratégica da subsidiária, de seus gerentes, e das redes de fornecedores locais. Em outras palavras, ele desafiou o discurso de que o 'mercado' levaria ao fim as práticas imperialistas das grandes corporações (Prahalad \& Liebhertal, 2003): 'as outras (montadoras) que estão chegando (ao Brasil) operam da mesma forma... se fosse na CAR (artifício usado pelo autor para não revelar o nome da montadora) haveria mais confiança, mais autonomia, entende? Lá (na CAR) eles trabalham de outra forma...' [mostrando interesse em se transferir para a CAR ou para o exterior]. Essas narrativas - com apoio em outras fontes de dados e por narrativas obtidas nos outros casos investigados - indicaram que a propaganda corporativa e a mobilização de atores e recursos políticos locais eram muito mais efetivos do que recursos e habilidades gerenciais privilegiados pelos acadêmicos. 
Em outra situação no Brasil, um informante-chave confirmou que procedimentos contábeis anunciados pelas montadoras e reportados pela mídia local não eram seguidos: 'é claro que não há transparência [risos]... nós passamos um sufoco aqui para manter nossa posição (como gerente de rede) e atender a demanda que eles fizeram... eles alegaram que o fornecedor concorrente podia cobrir nossa oferta... não temos a mínima idéia se eles (a montadora) estavam blefando... o vice-presidente deles é bom de mídia... no fundo, o que eles anunciam como estratégia de fornecimento não passa de um grande leilão' [demonstrando irritação].

Essas narrativas ressaltavam três mecanismos no domínio do 'real': (a) redução de importância estratégica das subsidiárias; (b) substituição de fornecedores locais por fornecedores ou redes de outros países preferidos pelas matrizes, e (c) aquisição de fornecedores locais por grandes empresas estrangeiras que se transformaram em subsidiárias com pouca autonomia estratégica. Essas narrativas eram corroboradas pelas aquisições, no Brasil, de importantes empresas fornecedoras nacionais por grupos estrangeiros, pelo enxugamento e achatamento dos quadros de funcionários do setor automotivo e de outros setores, pelo esvaziamento do sindicato na região do $\mathrm{ABCD}$ paulista, e pela reestruturação 'geopolítica' do setor no Brasil em função dos acordos controversos entre municípios (Betim-MG, São José dos Pinhais-PR, Juiz de Fora-MG, Porto Alegre-RS, Resende-RJ, SalvadorBA) e as montadoras (Arbix \& Zilbovicius, 1997; Rodríguez-Posé \& Arbix, 2001).

$\mathrm{Na}$ Inglaterra, narrativas similares foram produzidas por informantes que não foram tratados como informantes-chave pelo pesquisador. Esses informantes puderam abdicar do papel de 'estrategista' imposto pelo pesquisador e isso facilitou a transição desde o empírico para o real em suas narrativas. Em uma dessas entrevistas um diretor de um gerente de rede reclamou do uso de poder pelas montadoras e a decrescente autonomia daquela subsidiária: 'Você precisa entender... essa empresa (o gerente de rede investigado) é uma grande multinacional ... Não é fácil para eles (a montadora) gerenciar isso tudo... Acho até que essa empresa, como corporação, é maior do que essa montadora... esses fornecedores (do segundo nível) são empresas familiares ou apenas pequenas empresas. Seria moralmente errado transferir essa pressão toda para cima deles. Isso é quase chantagem moral, entende? A montadora... em muitos momentos [baixando o tom de voz] gostaria que nós fizéssemos isso (referindo-se à montadora na Inglaterra e também, à matriz nos EUA). Nossa filosofia de negócios (aqui) não é de quebrar ninguém'. [demonstrando insegurança e tensões organizacionais locais].

Entrevistas com o informante de um dos fornecedores desse gerente de rede confirmaram que a empresa enfrentava um quadro de decrescente autonomia 
em relação à matriz nos EUA. Para gerenciar 'estrategicamente' a rede local de fornecedores a empresa tinha que obedecer a 'certas' ordens. Esses resultados sugerem que mecanismos e estruturas de controle vertical usados por empresas globais (Ghoshal \& Gratton, 2002) são mais importantes para a prática e para a compreensão da gerência estratégica desse tipo de rede do que o princípio de 'cooperar para competir' ou outras 'complexidades' ressaltadas por pesquisadores.

Por sua vez, um alto diretor da montadora mencionada pelo informante-chave (do gerente de rede) argumentou que a maioria das informações fornecidas por aquela empresa dos EUA, que passava segundo ele por um acelerado e suspeito processo de expansão de vendas e de ocupação de 'mercados' na Europa, devia ser encarada como propaganda corporativa. Esse tipo de recurso camuflava outras estratégias, de natureza político-econômica, bem mais efetivas. O informante sugeriu que a decisão do gerente da rede de cooperar com aquela montadora, a mais importante da Inglaterra em termos econômicos e políticos e que havia sido recentemente adquirida por um grande grupo da Alemanha, era parte da estratégia de construir a impressão (Mendonça \& Amantino-de-Andrade, 2003) de comprometimento com o 'mercado' e instituições locais.

Aquele informante sugeriu que pesquisas acadêmicas que comprovassem que as redes e, mais especificamente, as estratégias cooperativas implementadas por gerentes de redes elevam a competitividade empresarial, industrial ou nacional estavam relacionadas à estratégias mais amplas focadas na redução da influência do Estado e de outras forças sociais locais sobre o setor automotivo inglês (e sobre outros setores): 'estou certo de que você está prestando atenção a isso... quero dizer, a como eles (o gerente de rede) conseguiram essa súbita transformação. Em pouco menos de cinco anos aqui na Inglaterra eles já se tornaram um de nossos principais fornecedores... quais métodos de trabalho eles usam? Esse é o tipo de resposta que você deveria buscar. Porque, se eles de fato descreverem a metodologia com que eles trabalham...' [demonstrando seriedade e introspecção].

Nos dois países, as narrativas se referiam à invasão do 'mercado' local por grandes corporações estrangeiras e a conseqüente formação de redes em um nível mais elevado da realidade. Na Inglaterra, as principais questões, todas iniciadas no governo liberal de Thatcher, eram o controverso processo de desnacionalização da indústria automotiva, o estabelecimento do regime neoliberal da 'nova competição' (Best, 1990), e o take-over de cidades da Inglaterra por grandes montadoras (Oliver \& Wilkinson, 1992). No Brasil, as principais questões eram o processo de desregulamentação iniciado pelo governo liberal de Collor e a reestruturação do setor por meio de investimentos feitos pelas grandes montadoras (em ausência de investimentos do Estado), iniciado em 1995, durante 
o governo neoliberal de Henrique Cardoso, no chamado 'Novo Regime Automotivo' (Rodríguez-Pose \& Arbix, 2001). No conjunto, as narrativas nos dois países se referiam ao processo de estabelecimento do chamado capitalismo global e a práticas estratégicas igualmente complexas e controversas.

Esses mecanismos, estruturas e redes de poder não vêm sendo privilegiados por pesquisadores da área de estratégia. Isso ajuda a explicar por que a literatura de redes verticais tampouco reconhece tais questões. A hegemonia gerencial que se constituiu na área é um dos principais obstáculos. Por causa dessa hegemonia, pesquisadores da área, principalmente nos EUA, abandonaram o caráter político da estratégia empresarial e as interfaces entre governo e empresa, apesar da sua crescente importância no contexto do capitalismo global.

Os resultados indicam que, nos dois países, as estratégias cooperativas investigadas eram causadas principalmente por mecanismos, estruturas e redes 'que 'residem' em um nível mais elevado da realidade. Tais mecanismos, estruturas e redes tendem a reduzir a autonomia de empresas, gerentes e governos locais e a fortalecer a posição político-econômica das matrizes de grandes corporações em diferentes países. Essas descobertas desafiam a hegemonia gerencial na área e a histórica distinção que se faz entre estratégia empresarial e política pública.

\section{Uma Proposta de Framework: Reconhecendo Supra-redes e Redes Gerenciais}

Com base na ontologia do realismo crítico e no critério de plausibilidade, o framework aqui proposto pode ajudar a descrever e a explicar o desempenho e a gerência estratégica em redes verticais (ver Figura 1). Esse framework se baseia em uma representação vertical de redes e sugere que as supra-redes que 'residem' em um domínio da realidade pouco acessível para pesquisadores e as estratégias correspondentes no âmbito público-privado parecem mais importantes para o desempenho de grandes corporações do que as redes do tipo inter-firma.

As supra-redes, parecidas com "ego-redes" (ver Lima, Macedo-Soares, \& Tauhata, 2004, p. 753), desafiam nossas pressuposições das fronteiras, não somente entre a empresa e o ambiente/mercado, mas também entre o público e o privado. Elas são mais abrangentes e complexas do que a elite corporativa, composta por executivos e diretores de grandes corporações (Davis, Yoo, \& Baker, 2003). Supra-redes estão intimamente relacionadas à expansão do capitalismo global (Sklair, 1995) e parecem ser constituídas pelo alto escalão das grandes corporações, membros locais e estrangeiros da classe política, indústria da mídia, membros da academia, e outros membros da elite (Faria, 2004b). 


\section{Figura 1: Níveis de Redes Estratégicas e de Performance}

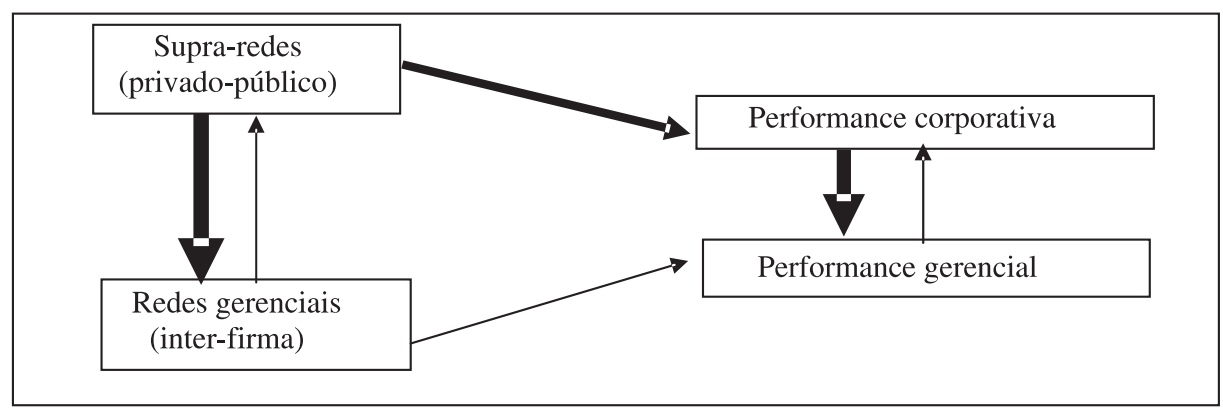

Assim como membros da chamada elite gerencial (Pettigrew, 1992b), os constituintes das supra-redes tentam camuflar seu poder político-econômico por meio da construção de impressões. Para eles é conveniente, por exemplo, que entendamos que as estratégias ocorrem no nível gerencial das redes. Isso significa que, de um modo ou de outro, os modelos mais conhecidos no âmbito de redes e a hegemonia gerencial na área de estratégia funcionam como aliados dos constituintes das supra-redes.

O framework sugere que pesquisadores diferenciem o locus da 'gerência estratégica' e o das práticas efetivamente estratégicas (ver Varadarajan \& Clark, 1994) em suas investigações e que as supra-redes 'governam' - não quer dizer que 'dominam' - as redes gerenciais no nível inter-firma. Pesquisas futuras devem identificar como e em que medida supra-redes restringem ou capacitam os processos e o desempenho das redes gerenciais e vice-versa. Nesse sentido, o framework também sugere que sejam reconhecidos o caráter político da estratégia e do mercado e o caráter econômico da política (Martin, 2003). Finalmente, sugere que se reconheça que grandes empresas não são 'entidades autônomas', mas membros importantes de supra-redes capazes tanto de moldar 'mercados'/ 'ambientes' quanto de influenciar conhecimento acadêmico.

As articulações políticas e econômicas entre empresas e governo vêm sendo priorizadas pelas estratégias de corporações transnacionais segundo a literatura focada na análise do capitalismo global. Essa literatura, que ainda não chamou a atenção da grande maioria de acadêmicos da área de estratégia, vem mostrando que a cooptação de membros do âmbito público (ver Korten, 1995; Monbiot, 2000), principalmente em países menos desenvolvidos, é muito mais efetiva para a conquista e manutenção de 'mercados' do que práticas e estratégias de nível gerencial.

A investigação de tais mecanismos em pesquisas futuras implica requerer o reconhecimento da distância entre o domínio do 'empírico' - que é o locus da 
estratégia onde a maioria dos pesquisadores obtém os 'dados' - e os domínios do factual e do real - que são os loci onde as decisões e práticas efetivamente estratégicas costumam ocorrer (Pettigrew, 1992b). Correspondentemente, o realismo crítico e o critério da plausibilidade parecem ser de grande importância para a descoberta dos mecanismos, estruturas e agentes do domínio do real que mais 'fazem diferença'.

\section{Considerações Finais e Implicações Futuras}

Este artigo demonstrou que a hegemonia gerencial e o princípio de 'cooperar para competir' que se constituíram na literatura de gerência estratégica precisa ser desafiada. Essas bagagens levaram não somente à supressão dos argumentos de que redes verticais podem facilitar a formação de cartéis e o bloqueio da competição (Jorde \& Teece, 1989). Este artigo demonstrou que, no contexto do capitalismo global, essas bagagens dificultam o reconhecimento de que grandes corporações supra-redes, em nível mais elevado da realidade, com propósito ainda mais importante: dissolver resistências políticas e institucionais em diferentes países ou 'mercados'. Pesquisas empíricas indicam que essa realidade se aplica tanto a grandes empresas estrangeiras no Brasil quanto a empresas brasileiras no exterior (ver Guedes \& Faria, 2004).

O framework proposto neste artigo mostra que as redes gerenciais e as supraredes residem em níveis distintos da realidade, e que as primeiras estão subordinadas às segundas. Essas supra-redes desafiam os debates recentes na literatura, centrados no nível inter-firma e baseados nas abordagens apolíticas 'de dentropara-fora' e 'de fora-para dentro'. Mais especificamente, as supra-redes desafiam a distinção que a área de estratégia faz entre os domínios do público e do privado e o pressuposto de que o que gerentes fazem ou deixam de fazer tem importância fundamental para o desempenho de grandes empresas ou redes.

Este artigo sugere que a aplicação do framework aqui proposto em pesquisas futuras requer que pesquisadores desafiem também o paradigma 'da empresa como entidade autônoma', o qual reproduz a hegemonia da academia dos EUA na área de estratégia. Tendo em vista a não neutralidade histórica dessa área e também a participação - involuntária ou não - de membros da academia nas supra-redes, o autor deste artigo argumenta que a ontologia de realismo crítico é importante, mas insuficiente para a superação de tais obstáculos epistemológicos e disciplinares.

É preciso aqui ressaltar que a autonomia da área de estratégia vem sendo questionada, em especial na Europa, não somente devido a práticas controversas 
de grandes corporações em diferentes países, mas também devido à crescente influência dessas organizações sobre acadêmicos e instituições acadêmicas (Whittington, Jarzabkowski, Mayer, Mounoud, Nahapiet et al., 2003). Argumentamos então que outros mecanismos e agentes, em nível mais elevado da realidade, deveriam encorajar o desenvolvimento de conhecimento mais crítico na área de estratégia no Brasil. Independentemente disso, com base nas descobertas aqui apresentadas, argumentamos que pesquisadores no Brasil devem desafiar as fronteiras que a academia, em especial nos EUA, construiu entre acadêmicos e praticantes e entre as áreas de estratégia e de gerência e entre as áreas de estratégia e de política pública e gestão pública. Em outras palavras, o framework aqui proposto poderá alcançar sua efetiva relevância, no Brasil e em outros países, se aplicado tanto por pesquisadores quanto por praticantes dessas diferentes áreas.

\section{Artigo recebido em 11.11.2004. Aprovado em 18.05.2005.}

\section{Agradecimentos}

$\mathrm{O}$ autor gostaria de agradecer as sugestões feitas em especial por um revisor anônimo da RAC e pelas observações feitas pelo Prof. Sérgio Rezende, da PUC-Minas, para versão preliminar deste artigo.

\section{REFERÊNCIAS BibLIOGRÁfICAS}

Ackroyd, S., \&

Fleetwood, S. (Eds.). (2000).

Realist perspectives on management and organizations. London: Routledge.

Aktouf, O. (2002).

Governança e pensamento estratégico: uma crítica a Michael Porter. Revista de Administração de Empresas, 42(3), 43-53.

Alvesson, M., \&

Deetz, S. (2000).

Doing critical management research. London: Sage.
Alvesson, M., \&

Willmott, H. (1992).

On the idea of emancipation in management and organization studies. Academy of Management Review, 17(3), 432-465.

Alvesson, M., \&

Willmott, H. (1996).

Making sense of management. London: Sage.

Arbix, G., \&

Zilbovicius, M. (Eds). (1997).

De JK a FHC. A reinvenção dos carros. São Paulo: Scritta. 
Axelsson, B., \&

Easton, G. (Eds.). (1992).

Industrial networks: a new view of reality. London: Routledge.

Best, M. (1990).

The new competition - institutions of industrial restructuring. Cambridge: Polity Press.

Bhaskar, R. (1989).

The possibility of naturalism: a philosophical critique of the contemporary human sciences (2nd ed.). Hemel Hampstead: Harvester Wheatcheaf.

Bhaskar, R. (1997).

$A$ realist theory of science ( 2 nd ed.).

London: Verso.

Bohman, J. (1996).

Critical theory and democracy. In D. Rasmussen (Ed.). The handbook of critical theory (pp. 190-215). Oxford: Blackwell.

Chandler, A. (1962).

Strategy and structure: chapters in the history of the american industrial enterprise. Cambridge, MA: MIT Press.

Davis, G.,

Yoo, M., \&

Baker, W. (2003).

The small world of the American corporation elite, 1982-2001. Strategic Organization, 1(3), 301-326.

Dobnie, C., \&

Luffman, G. (2000).

Implementing marketing strategy through a market orientation. Journal of Marketing Management, 16(8), 895-916.
Dunlop, J. (Ed.). (1980).

Business and public policy. Boston, MA: Harvard University.

Easterby-Smith, M.,

Thorpe, R., \&

Lowe, A. (1991).

Management research: an introduction. London: Sage.

Eisenhardt, K. (1989).

Building theories from case study research. Academy of Management Review, 14(4), 532-550.

Faria, A. (2004a).

Em busca de relevância no âmbito de estratégia de marketing. Anais do Encontro Nacional dos Programas de Pós-Graduação em Administração, Curitiba, PR, Brasil, 28.

Faria, A. (2004b).

Theorising networks from a critical realist standpoint. In S. Fleetwood, \& S. Ackroyd (Eds.). Critical realist applications in organisation and management studies. London: Routledge.

Foss, N. (2001).

The boundary school. In H. Volberda \& T. Elfring (Eds). Rethinking strategy. London: Sage.

Ghoshal, S., \&

Gratton, L. (2002).

Integrating the enterprise. Sloan Management Review, 44(1), 31-38.

Golden, B. (1997).

Further remarks on retrospective accounts in organizational and strategic management research. Academy of Management Journal, 40(5), 1243-1252. 
Guedes, A., \&

Faria, A. (2004).

Entendendo governança internacional: estudo de caso no setor de petróleo. Organizações \& Sociedade, 11(31), 171-185.

Gulati, R.,

Nohria, N., \&

Zaheer, A. (2000).

Guest editors' introduction to the special issue on strategic networks. Strategic Management Journal, 21(3), 199-201.

Habermas, J. (1987).

Conhecimento e interesse. Rio de Janeiro: Guanabara.

Hakansson, H., \&

Ford, D. (2002).

How should companies interact in business networks? Journal of Business Research, 55(2), 133-139.

Hitt, M.,

Ireland, R., \&

Hoskisson, R. (2002).

Administração estratégica. São Paulo: Thomson.

Jorde, T. M., \&

Teece, D. J. (1989).

Competition and cooperation: striking the right balance. California Management Review, 31(3), 25-37.

Knights, D., \&

Morgan, G. (1991).

Strategic discourse and subjectivity: towards a critical analysis of corporate strategy in organizations. Organization Studies, 12(2), 251-273.
Kohli, A., \&

Jaworski, B. (1990).

Market orientation: the construct, research propositions, and managerial implications. Journal of Marketing, 54(2), 46-54.

Korten, D. (1995).

When corporations rule the world. Bloomfield: PCD Forum.

Lamming, R. (1993).

Beyond partnership: strategies for innovation and lean supply. London: Prentice Hall.

Locke, R. (1996).

The collapse of the american management mystique. New York: Oxford University.

Lorenzoni, G., \&

Baden-Fuller, C. (1995).

Creating a strategic center to manage a web of partners. California Management Review, 37(3), 146-163.

Macedo-Soares, T.,

Lima, F.,

Macedo-Soares, D., \&

Tauhata, T. (2004).

Redes estratégicas no setor de aviação: o caso Varig - Star Alliance. Revista Brasileira de Administração Pública, 38(5), 751-777.

Martin, N. (2003).

A estratégia empresarial de captura do poder político. Anais do Encontro Nacional dos Programas de PósGraduação em Administração, Atibaia, SP, Brasil, 27. 
Mendonça, J., \&

Amantino-de-Andrade, J. (2003).

Gerenciamento de impressões: em busca de legitimidade organizacional. Revista de Administração de Empresas, 43(1), 36-48.

Miles, M., \&

Huberman, A. (1994).

Qualitative data analysis. London: Sage.

Mintzberg, H. (1990).

The design school: reconsidering the basic premises of strategic management. Strategic Management Journal, 11(3), 171-195.

Mir, R., \&

Watson, A. (2000).

Strategic management and the philosophy of science: the case for a constructivist methodology. Strategic Management Journal, 21(9), 941-953.

Monbiot, G. (2000).

Captive state: the corporate takeover of Britain. London: Macmillan.

Oliver, N., \&

Wilkinson, B. (1992).

The japanization of british industry. Oxford: Blackwell.

Pettigrew, A. M. (1992a).

The character and significance of strategy process research. Strategic Management Journal, 13(Special Issue), 5-16.

Pettigrew, A. M. (1992b).

On studying managerial elites. Strategic Management Journal, 13(Special Issue), 163-182.
Porter, M. (1980).

Competitive strategy: techniques for analyzing industries and competitors. New York: Free Press.

Porter, M. (1985).

Competitive advantage: creating and sustaining superior performance. New York: Free Press.

Porter, M. (1990).

The competitive advantage of nations. New York: Free Press.

Porter, M. (1996).

What is Strategy? Harvard Business Review, 74(6), 61-78.

Prahalad, C., \&

Lieberthal, K. (2003).

The end of corporate imperialism. Harvard Business Review, 81(3), 109117.

Rodrígues-Pose, A., \&

Arbix, G. (2001).

Strategies of waste: bidding wars in the brazilian automotive sector. International Journal of Urban and Regional Research, 25(1), 134-154.

Rumelt, R. (1996).

The many faces of Honda. California Management Review, 38(4), 103-111.

Sayer, A. (1992).

Method in social science: a realist approach (2nd ed.). London: Routledge.

Shrivastava, P. (1986).

Is Strategic management ideological? Journal of Management, 12(3), 363377. 
Sklair, L. (1995).

A sociologia do sistema global. Petrópolis: Vozes.

Tsoukas, H. (1994).

What is management? An outline of a metatheory. British Journal of Management, 5(4), 289-301.

Varadarajan, P., \&

Clark, T. (1994).

Delineating the scope of corporate, business, and marketing strategy. Journal of Business Research, 31(23), 93-105.

Webster, R. (1992).

The changing role of marketing in the corporation. Journal of Marketing, 56(4), 1-17.

Wensley, R. (1995).

A critical review of research in marketing. British Journal of Management, 6(s1), s63-s82.
Wernerfelt, B. (1984).

A resource-based view of the firm. Strategic Management Journal, 5(2), 171-180.

Whittington, R. (2001).

$O$ que é estratégia. São Paulo: Pioneira.

Whittington, R., Jarzabkowski, P., Mayer, M.,

Mounoud, E.,

Nahapiet, J., \&

Rouleau, L. (2003).

Taking strategy seriously. Journal of Management Inquiry, 12(4), 396-409.

Womack, J.,

Jones, D., \&

Roos, D. (1990).

The machine that changed the world. New York: Rawson Associates.

Yin, R. (1994).

Case study research - design and methods. London: Sage. 